\title{
Community Benefit Report Spending and Content Analysis
}

\author{
Orry Swift \\ Lamar University \\ Ricardo Colon \\ Lamar University
}

\begin{abstract}
There is substantial debate regarding the community benefits provided by nonprofit hospitals in exchange for tax-exempt status at the federal and state levels. Despite the controversy surrounding this topic, research into community benefit spending is a relatively new area of academic research. This study examines community benefit reports from nonprofit hospitals in the California Office of Statewide Health Planning and Development (OSHPD) database. We employ text-based content analysis to determine how the language used in current-year reports impacts community benefit spending in the following year. Our study contributes to the literature because it is the first paper that conducts text-based content analysis of community benefit reports using the following five textual characteristics: length, boilerplate, fog, specificity, and tone. We find that the length, specificity, and tone of the reports significantly impact community benefit spending.
\end{abstract}

Keywords: nonprofit, disclosures, content analysis, community benefits

\section{INTRODUCTION}

Hospitals in the United States were originally formed as charitable institutions with the intent of serving the financially indigent populace and the general public (Kennedy et. al., 2010). Until the 20th century, there were no economic incentives for hospitals to exist as nonprofit entities. The Hill-Burton Act of 1946 was the first legislation to provide such incentives: it provided grants to nonprofit hospitals, requiring them to provide 20 years' worth of charity service, as part of its program to improve healthcare in the United States (MFH, 2005). Throughout the next three decades, the Internal Revenue Service (IRS) adapted its requirements for charity care several times, stating that hospitals needed to provide charity care to maintain tax exemption, then adding "community benefits" to the charity care requirements (Wang \& Wambsganns, 1996).

Today, hospitals are expected to step outside their traditional roles to address the social, economic, and environmental factors that contribute to poor health in the communities that they serve by providing community benefits (AdventistHealth, 2020). These community benefits are essential for the tax-exempt status of hospitals at the state and federal level. Most hospitals in the U.S. operate as nonprofit organizations and are exempt from most federal, state, and local taxes in acknowledgment of the community benefit provided by these institutions (Health Affairs, 2016). More importantly, federal tax-exempt status hinges upon the requirement that nonprofit hospitals engage in activities that benefit the communities that they 
serve by providing charity care and incurring spending that promotes community health (Health Affairs, 2016).

The IRS has expanded the activities that count as community benefit beyond charity care to include items such as the difference between what Medicaid costs and what Medicaid actually pays for, costs of other means tested government programs, community health improvement, health professions education, subsidized health services, research, and cash and in-kind contributions for community benefit (Internal Revenue Service, 2020). The Patient Protection and Affordable Care Act (ACA) enacted in 2010 added section 501(r) to the Internal Revenue Code containing additional community benefits requirements. These new requirements address a hospital organization's financial assistance policy, billing and collections requirements, limits on hospital charges for eligible patients, and conducting community health needs assessments (CHNA) and developing community health improvement plans (CHIP) to address the most important needs at least once every three years (Rozier, 2020). Importantly, the new federal law requirements do not establish a minimum value of community benefits that a hospital must provide to qualify for tax exempt status (James, 2016). State tax exemption is determined by the individual states' laws. Unlike federal law, at least five states require a minimum level of hospital spending in community benefits as of 2021 (Hilltop Institute, University of Maryland Baltimore County, n.d.)

The majority of states have established community benefits reporting requirements. For instance, the state of California has a longstanding law that requires nonprofit hospitals to prepare community benefits plans and report the economic value of community benefits provided, and to file the plan with the Office of Statewide Health Planning and Development (OSHPD), which makes the reports available to the public (Cal. Health \& Safety Code $\S 127350,1994)$. Either biannually or every time a significant change is made, each hospital must provide to the OSHPD a copy of its discount payment policy, charity care policy, eligibility procedures and policy review process, and the application for charity care or discounted programs, information which OSHPD makes available to the public (Cal. Health \& Safety Code $\S 127435$, 1994).

There has been widespread controversy about the community benefits provided by nonprofit hospitals and many calls for reform. The main issue appears to be whether nonprofit hospitals truly benefit their communities. These concerns have been seen in the media, health policy organizations, academia, and governmental regulation at the federal and state levels. Studies on community benefits spending often derive their data from IRS Form 990 and Schedule H, where nonprofit hospitals report the value of community benefits (Chaiyachati et al., 2018; Leider et al., 2017). Other studies use Medicare and Medicaid Services (CMS) healthcare cost reports (Nonprofit, For-Profit, and Government Hospitals Uncompensated Care and Other Community Benefits: Committee on Ways and Means, House of Representatives, 2005; Milken Institute School of Public Health, n.d.). A report by the Lown Institute summarizes frequent findings on studies regarding community benefit spending and reporting as follows: (1) community benefit spending among nonprofit hospitals varies widely; (2) some hospitals spend more on programs that directly impact community health; (3) there seems to be little accountability from the government to incentivize community benefit spending: and (4) reporting methods are not standardized across hospitals and states (Garber et al., 2020).

This study is different from prior research into community benefits for two reasons: first, it does not analyze data provided on IRS Form 990 or CMS cost reports and, second, it does not seek to determine the impact of nonprofit hospitals in their communities. Instead, this study conducts text-based analysis of Community Benefit Reports (CBR) of nonprofit hospitals in California to determine whether the language used in the report impacts the amount of community benefit spending in the following year. Specifically, this study analyzes the following textual characteristics of CBRs: length, boilerplate, fog, specificity, and tone. Content analysis, of which text based analysis is a subset, has been widely used in research in disciplines including business policy and strategy, managerial and organizational cognition, research methods, organizational behavior, human resources, social-issues management, technology and innovation management, international management, and organizational theory (Duriau et al., 2007).

We make two significant contributions to existing literature on nonprofit hospitals' community benefits. First, to the authors' knowledge, it is the first study to employ textual analysis to determine whether 
the language used in a CBR impacts the amount of community benefit spending in the following year. Second, this study finds a significant relationship between the report length, specific language, and tone in the amount of community benefits spent in the subsequent year. This finding-a significant increase in community benefits spending based on certain report textual characteristics-is our contribution to the literature.

Part II of this article examines prior literature with respect to research on community benefits spending. Part III applies the textual analysis measures from prior research studies (i.e. fog, length, specificity, boilerplate, and tone) to develop our hypothesis considering our variable of interest, change in community benefits spending by nonprofit hospitals. We ultimately conclude that the length, specificity, and tone of CBRs have a significant impact on hospitals' community benefits spending the year after the report is published.

\section{PRIOR LITERATURE}

This study draws upon prior research on nonprofit hospitals, particularly work that examines community benefit spending. Community benefits is emerging as a new field of academic and policy research and it can be challenging to identify articles about U.S. nonprofit hospital community benefits (Rozier, 2020; Tao et al., 2010). In a recent study of research on community benefits, Michael D. Rozier identified 96 papers dealing with community benefits and classified them in the following topical areas: background information on community benefits, governance and ethics, community needs assessment process, assessment content, assessment effect, community programs, impact and evaluation, spending and finance basics, spending and finance relationships, population health, and policy proposals (2020).

For purposes of this study, we will focus on research that directly or indirectly conducts content analysis related to community benefits spending. A study conducting content analysis of publicly available community health needs assessments (CHNAs) and implementation strategies found that all of the needs assessments included at least one implicit health equity term (disparities, disadvantage, poor, or minorities); $65 \%$ included at least one explicit health equity term (equity, health equity, inequity, or health inequity); $35 \%$ of implementation strategies included one or more explicit health equity term, but only $9 \%$ included an explicit activity to promote health equity (Carroll-Scott et al., 2017). A different study evaluated CHNA and implementation strategies reports based on 16 content criteria and found that higher quality reports were associated with consultant-led CHNA processes and collaboration with local health departments (Pennel et al., 2015).

Alfano-Sobsey et al. (2014) conducted research to describe the collaboration of organizations that conducted a joint community health needs assessment in Wake County, NC. Their methodology included analysis of focus group discussions by inductive coding, that is, identifying themes that emerged from transcripts through examination and comparison. In a different study, the content of surveys gathered using community-based participatory research was analyzed to identify individual and community health priorities and determinants of health priorities (Akintobi et al., 2018). Powell et al. (2018) conducted content analysis of community health needs assessments and implementation strategies of nonprofit hospitals in Philadelphia and found that in many cases there is little alignment between the needs identified in assessments and the strategies targeted in the implementation strategies.

Another strand of research seeks to study associations or relationships between community benefits spending and other variables. Worthy and Anderson (2016) compared Texas hospitals claiming tax-exempt status for federal income tax purposes to other hospitals in the state and concluded that, on average, taxexempt hospitals spent 100 times more on community benefits than non-exempt hospitals. Johnson et al. (2019) studied the association between community benefit laws and community benefits spending and found that being subject to any state law on community benefits resulted in greater community service spending. Singh et al. (2018) also find an association between community benefits spending and state regulation concluding that adoption of community service-related laws and regulations was consistently associated with higher levels of hospital provided community benefits, possibly because regulations send a strong signal to hospitals that more spending is expected. Looking at a possible tradeoff between providing 
charity care and levels of community benefits spending, Singh (2013) studied community benefit reports of nonprofit hospitals in Maryland and found that hospitals did not engage in trade offs between charity care and community benefits spending. In a study investigating the relationship between the spending patterns of local health departments and nonprofit hospitals' community benefits spending, Singh and Young (2017) found that hospital community benefit spending was unrelated to how much local public health agencies spent, per capita, on public health in their communities. Young et al. (2018) looked at the association between the ACA and community benefit spending and found a positive association between the ACA and higher total community benefit spending.

Despite prior research on the area of community benefit spending, the authors did not identify any studies where content analysis was conducted to determine the relationship between the content of a community benefit report and the amount of community benefit spending in the following year. Similarly, there are no prior studies with respect to community benefit spending that consider the textual characteristics of interest in this study: length, boilerplate, fog, specificity, and tone.

\section{HYPOTHESIS DEVELOPMENT}

Prior research on content analysis of community benefits has not considered the textual characteristics of interest in this study. For this reason, we will develop our hypothesis borrowing from academic papers in accounting and finance, where our variables of interest have been studied more extensively.

\section{Length}

In one study, Leuz and Schrand (2009) found a relationship between the occurrence of the Enron fraud scandal and the length of the financial statements issued after this event. In a subsequent study, Lang and Stice-Lawrence (2015) found a relationship between the adoption of International Financial Reporting Standards (IFRS) and the length of subsequent financial statement reports that were issued using these standards.

In this study, we expect to observe that the length of a CBR impacts the amount of community benefit spending in the year following the issuance of the report. We expect to see that longer reports are associated with unnecessary and irrelevant language which would not suggest additional benefit spending in the following year. Conversely, we expect to see that shorter reports are associated with more concise and relevant language about community health programs, which would be associated with additional spending in the following year.

\section{H1: The length of a community benefit report impacts community benefit spending in the following year.}

\section{Boilerplate}

We follow Dyer et al. (2017) and refer to boilerplate language as consisting of "generic and standardized disclosures" and "re-use of the same [entity's] disclosure from a prior period." Lang and SticeLawrence (2015) studied boilerplate on financial statements prepared under IFRS and found that it is correlated with liquidity, analyst following, and mutual fund ownership. McClane (2019) studied the use of boilerplate in securities deal making and found that it affected IPO costs. Overall, we expect to observe that boilerplate and generic disclosures in CBRs result in a decrease in community benefit spending in the following year because boilerplate text does not imply a commitment to additional spending.

H2: Boilerplate language use in a community benefit report decreases community benefit spending in the following year.

\section{Fog}

Fog represents a measure of the reading level of any given text. Taking into account Fog to analyze the effect of financial reporting by journalists on stock market performance, Dougal et. al (2012) defined Fog as "the number of years of formal education a reader of average intelligence would need to read and 
understand an article in one sitting" so that, as an example, a score of 12 would be appropriate for a high school graduate, a score of 7 would be appropriate for a 7th-grader, and so on. Li (2008) states that "the Fog index proposes that, assuming everything else to be equal, more syllables per word or more words per sentence make a document harder to read." Li used the Fog index and found that the annual reports of firms with lower earnings had a higher Fog index (i.e., the reports were harder to read). Lawrence (2013) used Fog to evaluate the effect of readability on investor behavior and found that individuals invest more in firms that have readable financial disclosures.

We expect CBRs to be drafted in language that is easy to understand by the communities which are affected by community benefit spending. Often, these communities consist of populations that may be composed of individuals with lower educational attainment and economically marginalized neighborhoods. Accordingly, we expect to observe that reports with high levels of Fog precede lower community benefit spending in the following year.

H3: The level of fog in a community benefit report decreases community benefit spending in the following year.

\section{Specificity}

Hope et al. (2016) introduced specificity into the academic literature to quantify the specificity of a firm's risk factor disclosures in the financial statements. Specificity is quantified based on "the number of specific entity names including names of persons, locations and organizations, quantitative values in percentages, money values in dollars, times, and dates scaled by the total number of words in that section." They found that more specific risk-factor disclosures benefit users of financial statements, that markets react positively to financial statements positively associated with specificity, and that financial statement analysts are more able to assess fundamental risks when risk-factor disclosures are more specific. Cazier et al. (2018) studied specificity and found that specific risk factor disclosures do not result in more favorable regulatory or judicial outcomes. Their study suggests that "longer and more boilerplate risk factor disclosures are less likely to be flagged as inadequate under judicial and regulatory review."

We expect that CBRs more positively associated with specificity will result in higher community benefit spending in the following year. More specific text suggests that hospitals have identified particular areas of need and health programs in which funds will be spent. Also, more specificity suggests additional disclosures and details with respect to the economic value of a hospital's community benefit spending. Conversely, less specificity would suggest that a hospital has not identified particular spending programs or that the hospital is providing less detail with respect to the economic value of its community benefit spending.

H4: The specificity of disclosures in a community benefit report increases community benefit spending in the following year.

\section{Tone}

Tone has been studied in the academic literature to determine its effect on earnings and stock prices. Studies have examined positive tone, negative (pessimistic) tone, and uncertain tone. For instance, Tetlock (2007) studied the use of positive and negative words by business journalists. He found that high media pessimism creates downward pressure on market prices and that unusually high or low pessimism is associated with high trading volume. Li (2010) found that future earnings and liquidity are better when the Management Discussion and Analysis (MD\&A) section of the financial statements is more positive. Rich et al. (2021) studied the relationship between the tone in the MD\&A section of the financial statements and the municipal debt market and found that a more negative tone is associated with higher future debt costs and greater future disagreements among bond rating agencies.

We expect that the tone of a CBR will impact community benefit spending in the following year. If a report uses a positive tone, it will be associated with higher community benefit spending in the following year. A positive tone would signal that the hospital is more optimistic and enthusiastic about the health 
benefits that it provides to the community and more committed to spending to support these programs. To the contrary, a negative tone would indicate that the hospital is less committed to the programs that it provides to the community and would be associated with less community benefit spending in the following year.

H5: The tone of a community benefit report impacts community benefit spending in the following year.

\section{METHODOLOGY AND RESULTS}

\section{Methodology}

The sample selection process is outlined in Table 1.

\section{TABLE 1 SAMPLE SELECTION}

\begin{tabular}{lc}
\hline Total hospital years in OSHPD database, 2012-2016 & 2,236 \\
For-profit hospital years & $(646)$ \\
Other institutional ownership & $(244)$ \\
Municipal ownership & $(410)$ \\
No ownership status reported & $(11)$ \\
Nonprofit hospital years with $<50 \mathrm{~m}$ total assets & $(370)$ \\
Hospitals with missing reports or incomplete financial data & $(54)$ \\
Multiply: years in sample & 5 \\
Missing data at least one year, all years excluded from sample & $(270)$ \\
\hline Non-profit hospital years & 285 \\
\hline
\end{tabular}

Using the OSHPD database (available at https:/oshpd.ca.gov/data-and-reports/costtransparency/hospital-community-benefit-plans), we examine community benefit reports for the five year period from 2012 to 2016 . The year 2016 only uses community benefit spending (CBS) data and not textual characteristics to conform with the time series regression. The OSHPD database includes 2,236 hospital years from 2012 to 2016 . We then exclude all hospitals that are not nonprofits, nonprofit hospitals with less than 50 million in total assets, and those with missing CBRs or incomplete financial data, arriving at a final sample that includes 285 nonprofit hospital years.

We use the following equation to examine our hypotheses:

$\mathrm{CBS}_{\mathrm{t}+1}=\alpha+\beta_{1}\left(\mathrm{FOG}_{\mathrm{t}}\right)+\beta_{2}\left(\mathrm{LENGTH}_{\mathrm{t}}\right)+\beta_{3}\left(\mathrm{BPLAVG}_{\mathrm{t}}\right)+\beta_{4}\left(\right.$ BPLMAX $\left._{\mathrm{t}}\right)$

$+\beta_{5}\left(\right.$ SPECIFICITY $\left._{\mathrm{t}}\right)+\beta_{6}\left(\right.$ NEGATIVE $\left._{\mathrm{t}}\right)+\beta_{7}\left(\right.$ POSITIVE $\left._{\mathrm{t}}\right)+\beta_{8}\left(\right.$ UNCERTAIN $\left._{\mathrm{t}}\right)+\varepsilon$

The Gunning-Fog index (FOG) measures the reading level of any given text using the following formula:

$\mathrm{FOG}=($ words per sentence + percentage of complex words $) * 0.4$, where complex words are words with at least 3 syllables.

We employ the Lingua:EN:Fathom Module in Perl to measure both FOG and LENGTH (Lang and Stice-Lawrence, 2015; Boritz et al., 2016; Bushee et al., 2018). This module analyses English text in a string or text file and computes the FOG index by counting the number of words, sentences, syllables (Lingua:EN:Syllable), and blank and non-blank text. To measure LENGTH, we use the natural logarithm transformation of the word count from Lingua:EN:Fathom to pare down large figures.

We measure SPECIFICITY following Hope et al. (2016). SPECIFICITY is defined as the number of specific words or phrases conveying specific information relevant to the nonprofit hospital divided by the 
total words in the community benefit report. We employ the Stanford Named Entity Recognizer (NER), an open-source software package, to count the seven entity categories referenced in community benefit reports: (1) names of locations, (2) names of organizations, (3) dates, (4) time, (5) names of people, (6) percentages, and (7) monetary values in dollars.

There are several common measures of tone in prior literature according to the Loughran McDonald English business dictionary (March 2019 version). These include a measure of negative tone, positive tone, and uncertain tone, among others (Feldman et al. 2010, Henry 2008, Kothari et al. 2009, Smith 2017). We restrict our measures of tone to this dictionary to help us identify tone usage in business writing and avoid including proper nouns or words from foreign languages. We measure NEGATIVE, POSITIVE, and UNCERTAIN using Loughran and McDonald's (2017) three accompanying word dictionaries to capture the tone of the disclosure. We converted the word lists to text files and extracted them into columns to import them into LIWC for use as a custom dictionary. The negative and uncertainty word dictionaries approximate the level of negative content discussed in the community benefit report. The positive dictionary captures any usage of tone besides the content in the negative and uncertain dictionaries. We use these dictionaries in the Linguistic Inquiry and Word Count software (LIWC) to analyze the counts of tone. LIWC reports the word counts for any given measure of tone in the dictionary for a given text file. We convert the community benefit report into a text file and pass it through LIWC for analysis after cleaning for nonrecognizable characters.

Boilerplate disclosure is a common construct in the textual analysis literature (McMullin 2016). Our measure of boilerplate disclosure, BPLAVG, is unique in that we do not compare text to a "corpus," or comprehensive text, to determine whether a disclosure is boilerplate. We employ a plagiarism software, WCopyfind, following prior literature in content analysis to make comparisons between text (Cazier and Pfeiffer 2015, McMullin 2016, Beatty et al. 2019) to make one-to-one comparisons with a hospital's own disclosures for the other four years of the sample. WCopyFind compares two documents side-by-side using certain textual parameters such as "shortest phrase to match" and "minimum \% of matching words" to measure the aggregate percentage of plagiarism between the two documents. We employ the shortest phrase to match as 4 words, with a minimum match to report as 4 , ignored all punctuation, and ignored all numbers.

These results produce a matrix for each hospital's disclosure, where each year of the five sample years has four unique results. We take these plagiarism percentages for each hospital year and average them across the four years, and then assign this figure to BPLAVG, or the average boilerplate figure when comparing a single hospital year to the other four hospital years. We measure BPLMAX as the maximum boilerplate disclosure within the matrix. We adopt this unique methodology for several reasons. First, there is no defined corpus in the existing literature on nonprofit hospitals. Second, we want to compare a hospital's community benefit report to itself rather than to other hospitals' community benefit reports. Third, because we have a matrix of results, an average seemed most appropriate to capture a meaningful boilerplate figure for testing.

\section{Results}

Table 2 presents the descriptive statistics for 57 unique nonprofit hospitals over the five-year sample period (2012-2016). 
TABLE 2

DESCRIPTIVE STATISTICS $(\mathrm{N}=\mathbf{2 8 5})$

\begin{tabular}{l|ccccc}
\hline \multicolumn{1}{c|}{ Variable } & Mean & Std Dev & $\begin{array}{c}\text { 25th } \\
\mathbf{\%} \text {-ile }\end{array}$ & Median & $\begin{array}{c}\text { 75th } \\
\text { \%-ile }\end{array}$ \\
\hline CBS & 0.1608 & 0.3339 & 0.0225 & 0.0379 & 0.0943 \\
FOG & 21.7453 & 2.2815 & 20.7500 & 22.4018 & 23.2029 \\
LENGTH & 9.4083 & 0.5996 & 8.9733 & 9.7158 & 9.8168 \\
BPLAVG & 0.5230 & 0.1643 & 0.4563 & 0.5650 & 0.6388 \\
BPLMAX & 0.6975 & 0.1946 & 0.6250 & 0.7300 & 0.8100 \\
SPECIFICITY & 0.1889 & 0.0647 & 0.1638 & 0.1771 & 0.2045 \\
NEGATIVE & 1.2047 & 0.3433 & 0.9400 & 1.1050 & 1.3950 \\
POSITIVE & 1.8171 & 0.3409 & 1.7050 & 1.8500 & 1.9600 \\
UNCERTAIN & 0.3293 & 0.1560 & 0.2300 & 0.2800 & 0.3700 \\
\hline
\end{tabular}

Community benefit spending expressed as a percentage of total spending (CBS) show a mean of $16.08 \%$, indicating that the average community benefit spending is well above the $1 \%$ required in other states (Hilltop Institute, 2021). The median of 3.79\% still meets this requirement and indicates that community benefit spending in California is high relative to other state requirements, likely due to the effects of Senate Bill 697 (Cal. Health \& Safety Code $\S 127350$, 1994). As previously mentioned, this bill requires hospitals to provide disclosures regarding community needs assessments and develop reports to meet those needs with accompanying financials.

We also find that SPECIFICITY - specific words or phrases conveying information relevant to the disclosing hospital divided by the total words in the community benefit report - has a mean of $18.89 \%$, indicating a substantial portion of the report has references to locations, organizations, dates, time, names of people, percentages, or monetary values in dollars. This is likely due to the audience of community benefit reports (donors, regulators, community, and managers) and their information needs. Community benefit spending revolves around the giving of the community and its people; therefore, we expect to see many names of individuals and organizations along with financial data in the disclosure.

Table 3 shows the Pearson and Spearman correlation coefficients for our sample of 285 community benefit reports. 


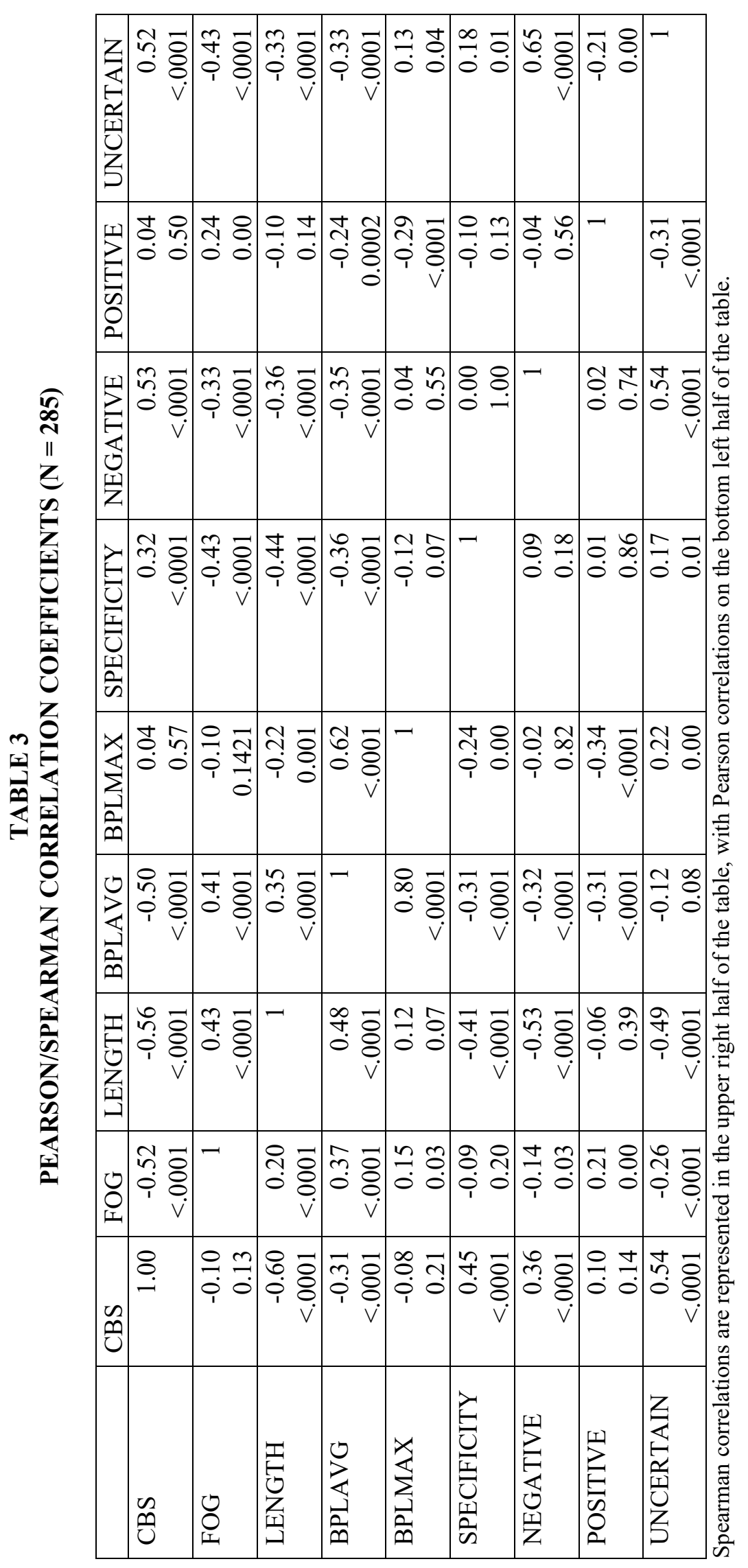

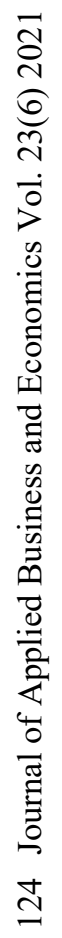


Both Pearson and Spearman reflect a negative correlation between LENGTH and CBS. As community benefit reports decrease in length, more concise and relevant prose leads to increased spending in the next year. BPLAVG also exhibits a negative correlation with CBS, implying that increased use of boilerplate language leads to less community benefit spending in the next year.

Table 4 presents the test of our five hypotheses on community benefit spending.

\section{TABLE 4 \\ IMPACT OF TEXTUAL CHARACTERISTICS OF COMMUNITY BENEFIT REPORTS ON COMMUNITY BENEFIT SPENDING $\left(\mathrm{N}=\mathbf{2 8 5}, \mathrm{R}^{2}=.5391\right)$}

\begin{tabular}{lclll}
\hline Variable & $\begin{array}{l}\text { Parameter } \\
\text { Estimate }\end{array}$ & $\begin{array}{l}\text { Standard } \\
\text { Error }\end{array}$ & t Value & Pr $>|\mathbf{t}|$ \\
\hline FOG & 0.0051 & 0.0081 & 0.63 & 0.5270 \\
LENGTH & $-0.1720^{* * *}$ & 0.0392 & -4.38 & $<.0001$ \\
BPLAVG & 0.1810 & 0.2362 & 0.77 & 0.4444 \\
BPLMAX & -0.1605 & 0.1691 & -0.95 & 0.3437 \\
SPECIFICITY & $1.2950^{* * *}$ & 0.2718 & 4.76 & $<.0001$ \\
NEGATIVE & -0.0534 & 0.0596 & -0.9 & 0.3711 \\
POSITIVE & $0.2115^{* * *}$ & 0.0539 & 3.92 & 0.0001 \\
UNCERTAIN & $1.0380^{* * *}$ & 0.1406 & 7.39 & $<.0001$
\end{tabular}

$* * *, * *$, and $*$ indicate significance at the $.01, .05$, and .10 levels, respectively.

We find that community benefit spending (CBS) is decreasing in the length of community benefit reports (LENGTH), with an $\mathrm{R}^{2}$ of .5391, which is significantly higher than traditional $\mathrm{R}^{2}$ in content analysis literature of .2 to .3 (Hope et al., 2016; Lang and Stice-Lawrence, 2015; Henry 2008). It is apparent from the $\mathrm{R}^{2}$ in this test that substantial variation in community benefit spending is explained by textual factors. The negative and significant coefficient on LENGTH of -.1720 suggests that shorter disclosures in year $\mathrm{t}$ lead to less community benefit spending in year $\mathrm{t}+1$, consistent with $\mathrm{H}_{1}$. The coefficient on SPECIFICITY is positive and significant (1.2950), implying that unit increases in SPECIFICITY will increase with community benefit spending in the next year. This suggests that more specific details in the current year will lead to more spending in the following year, supporting $\mathrm{H}_{4}$. The coefficient on POSITIVE (.2115), our measure of positive tone, implies that current year community benefit spending is increasing in prior-year positive tone, consistent with the assertion in $\mathrm{H}_{5}$.

We find that community benefit spending has no significant relationship with boilerplate language or the Gunning-Fog Index (FOG), indicating no support for $\mathrm{H}_{2}$ and $\mathrm{H}_{3}$. This is likely the case for boilerplate language because of a lack of readers among part of the intended audience of the disclosures - donors. The FOG index is fairly consistent across disclosures with a standard deviation on reading level of 2.28 and mean of 21.75, well within the college reading level range even at 3 standard deviations. Because reading level is already high for these disclosures relative to standard nonprofit/for-profit disclosures, it stands to reason that a unit change in FOG is less likely to impact community benefit spending.

\section{CONCLUSION}

There is ample debate on whether nonprofit hospitals provide enough economic benefits to the community in exchange for the federal and state tax exemptions that they receive. Also, most people who 
live in places where there is a nonprofit hospital are interested in knowing whether they are better off because they have a nonprofit hospital in the community (Rozier, 2020).

Prior research has focused on evaluating community benefit spending by analyzing spending reported on IRS Form 990 and Schedule H or studying Medicare and Medicaid Services (CMS) healthcare cost report. Academic research on the study of community benefit reports is a more recent development and studies conducting content analysis of the reports have focused on analyzing community health assessment plans and implementation strategies. Other studies have focused on the association between community benefit spending and federal and state regulation, spending by local public health agencies, or levels of charity care provided.

This is the first study to analyze the relationship between five textual characteristics of CBRs (i.e. length, boilerplate, fog, specificity, and tone) and community benefit spending in the year after the report is issued. We found that a shorter CBR leads to more community benefit spending in the following year, that more specificity leads to more spending in the following year, and that a positive tone leads to more spending in the following year. We did not find a significant relationship between fog and boilerplate language and community service spending in the following year. The main contribution of our paper to the literature is the finding of a significant increase in community benefit spending based on report length, specificity, and positive tone.

This study is subject to limitations. The main limitation is that we were only able to analyze California reports because of the lack of availability of the reports in many states. California makes information on community benefit reports widely available. Also, in states with community benefit reporting requirements, the state definition of community benefit is not necessarily the same definition used by the IRS to grant federal tax-exempt status, which leads to differences in the value of community benefits reported to the federal government in Form 990 and Schedule H, and the economic value of community benefits reported in state level community benefit reports.

This study has policy implications. First, taxpayers and communities would benefit if more states enacted laws requiring community benefit reporting. Content analysis of community benefit reports could be performed to forecast future funding of community benefits by nonprofit hospitals. Second, states could adopt similar definitions of what constitutes community benefit, so that comparisons of spending among states becomes more feasible. While our research is a first step in performing analysis of certain textual characteristics of CBRs, future research could consist of performing other types of content analysis to establish relationships between community benefit spending and the content of reports. Additionally, future research could consist of performing text-based analysis of CBRs to rank nonprofit hospitals in terms of their commitment to community benefit spending in a manner similar to the Lown Institute Hospitals Index (Garber et al., 2020). 


\section{REFERENCES}

Adventist Health Hanford \& Selma. (2020). 2019 Community Plan Update/Annual Report. Retrieved from https://www.adventisthealth.org/documents/community-benefit/2019-chp-updatear/Hanford_Selma_2019_Community-Health-Plan-Update-Annual-Report.pdf

Alfano-Sobsey E., Ledford S.L., Decosimo K., \& Horney J.A. (2014). Community health needs assessment in Wake County, North Carolina: Partnership of public health, hospitals, academia, and other stakeholders. North Carolina Medical Journal, 75(6), 376-383.

Akintobi, T.H., Lockamy, E., Goodin, L., Hernandez, N.D., Slocumb, T., Blumenthal, D., ... Hoffman, L. (2018). Processes and outcomes of a community-based participatory research-driven health needs assessment: A tool for moving health disparity reporting to evidence-based action.

Progress in Community Health Partnerships: Research, Education, and Action, 12(1S), 139-147. https://doi.org/10.1353/cpr.2018.0029

Beatty, A., Cheng, L., \& Zhang, H. (2019). Are risk factor disclosures still relevant? Evidence from market reactions to risk factor disclosures before and after the financial crisis. Contemporary Accounting Research, 36(2), 805-838.

Boritz, J.E., Hayes, L., \& Timoshenko, L.M. (2016). Determinants of the readability of SOX 404 reports. Journal of Emerging Technologies in Accounting, 13(2), 145-168.

Bushee, B.J., Gow, I.D., \& Taylor, D.J. (2018). Linguistic complexity in firm disclosures: Obfuscation or information? Journal of Accounting Research, 56(1), 85-121.

Cal. Health \& Safety Code $\S 127350$. (1994).

Cal. Health \& Safety Code $\S 127435$. (1994).

Carroll-Scott, A., Henson, R.M., Kolker, J., \& Purtle, J. (2017). The role of nonprofit hospitals in identifying and addressing health inequities in cities. Health Affairs, 36(6), 1102-1109. https://doi.org/10.1377/hlthaff.2017.0033

Cazier, R.A., \& Pfeiffer, R.J. (2015). Why are 10-K filings so long? Accounting Horizons, 30(1), 1-21.

Cazier, R.A., McMullin, J.L., \& Treu, J. (2018). Are lengthy and boilerplate risk factor disclosures inadequate? An examination of judicial and regulatory assessments of risk factor language. SSRN Electronic Journal. https://dx.doi.org/10.2139/ssrn.3167611

Chaiyachati, K.H., Qi, M., \& Werner, R.M. (2018). Non-profit hospital community benefit spending based on local sociodemographics. Journal of Health Care for the Poor and Underserved, 29(4), 1259-1268. https://doi.org/10.1353/hpu.2018.0093

Clary, A. (2019, July 25). States put community-benefits requirements to work for population health improvement. The Milblank Blog. Retrieved from https://www.milbank.org/2019/07/states-puthospital-community-benefits-requirements-to-work-for-population-health-improvement/

Cramer, G.R., Singh, S.R., Flaherty, S., \& Young, G.J. (2017). The progress of US hospitals in addressing community health needs. American Journal of Public Health, 107(2), 255-261.

Dougal, C., Engelberg, J., Garcia, D., \& Parsons, C. (2012). Journalists and the stock market. Review of Financial Studies, 25, 639-679.

Duriau, V.J., Reger, R.K., \& Pfarrer, M.D. (2007). A content analysis of the content analysis literature in organization studies: research themes, data sources, and methodological refinements. Organizational Research Methods, 10(1), 5-34. https://doi.org/10.1177/1094428106289252

Dyer, T., Lang, M., \& Stice-Lawrence, L. (2017). The evolution of 10-K textual disclosure: Evidence from Latent Dirichlet Allocation. Journal of Accounting and Economics, 64(2), 221-245.

Feldman, R., Govindaraj, J., Livnat, J., \& Segal, B. (2010). Management's tone change, post earnings announcement drift and accruals. Review of Accounting Studies, 15(4), 915-953.

Garber, J., Brownlee, S., \& Saini, V. (2020). Ranking hospital community benefit investment. Brookline, MA: The Lown Institute.

Glickman, A. (2019). How Do non-profit hospitals give back? A breakdown of community benefit spending. Health Policy Sense. Retrieved from https://ldi.upenn.edu/healthpolicysense/how-donon-profit-hospitals-give-back 
Health Affairs. (2016). Health policy brief: Nonprofit hospitals' community benefit requirements. Retrieved from https://www.healthaffairs.org/do/10.1377/hpb20160225.954803/full/healthpolicybrief_153.pdf

Henry, E. (2008). Are investors influenced by how earnings press releases are written? Journal of Business Communication 45, 363-407.

Hilltop Institute, University of Maryland Baltimore County. (n.d.). Community benefit state law profiles comparison. Retrieved from https://www.hilltopinstitute.org/our-work/hospital-communitybenefit/hcbp-state-comparison/

Hope, O., Hu, D., \& Lu, H. (2016). The benefits of specific risk-factor disclosures. Review of Accounting Studies, 21(4), 1005-1045.

Internal Revenue Service. (2020). Form 990, Schedule H. Retrieved from https://www.irs.gov/pub/irspdf/f990sh.pdf

James, J. (2016). Nonprofit hospitals' community benefit requirements. Project HOPE. https://doi.org/10.1377/hpb20160225.954803

Johnson, E.K., Hardy, R., Santos, T., Leider, J.P., Lindrooth, R.C., \& Tung, G.J. (2019). State laws and nonprofit hospital community benefit spending. Journal of Public Health Management and Practice, 25(4), E9-E17.

Kennedy, F.A., Burney, L.L., Troyer, J.L., \& Stroup, J.C. (2010). Do non-profit hospitals provide more charity care when faced with a mandatory minimum standard? Evidence from Texas. Journal of Accounting and Public Policy, 29(3), 242-258.

Kothari, S.P., Li, X., \& Short, J.E. (2009). The effect of disclosures by management, analysts, and financial press on the equity cost of capital: A study using content analysis. The Accounting Review, 84, 1639-1670.

Lang, M., \& Stice-Lawrence, L. (2015). Textual analysis and international financial reporting: Large sample evidence. Journal of Accounting and Economics, 60(2-3), 110-135.

Lawrence, A. (2013). Individual investors and financial disclosure. Journal of Accounting \& Economics, $56,130-147$.

Leider, J.P., Tung, G.J., Lindrooth, R.C., Johnson, E.K., Hardy, R., \& Castrucci, B.C. (2017). Establishing a baseline: Community benefit spending by not-for-profit hospitals prior to implementation of the Affordable Care Act. Journal of Public Health Management and Practice, 23(6), e1-e9. https://doi.org/10.1097/phh.0000000000000493

Leuz, C., \& Schrand, C. (2009). Disclosure and the cost of capital: Evidence from firms' responses to the Enron shock (No. w14897). National Bureau of Economic Research.

Li, F. (2008). Annual report readability, current earnings, and earnings persistence. Journal of Accounting \& Economics, 45, 221-247.

Li, F. (2010). The information content of forward-looking statements in corporate filings - A naïve Bayesian machine learning approach. Journal of Accounting Research, 48, 1049-1102.

McClane. (2019). Boilerplate and the impact of disclosure in securities deal making. Vanderbilt Law Review, 72(1), 191-295.

McMullin, J. (2016). Can I borrow your footnotes? Footnote boilerplate's learning externality.

Milken Institute School of Public Health, \& RTI International. (n.d.). Community Benefit Insight. Retrieved from http://www.communitybenefitinsight.org/?page=info.methods

Missouri Foundation for Health (MFH). (2005). Issue Overview: Hospital Charity Care in the United States. St. Louis, MO: MFH. Retrieved from http://www.mffh.org/HospitalChairtyCareIssueBrief.doc

Nonprofit, For-Profit, and Government Hospitals Uncompensated Care and Other Community Benefits: Committee on Ways and Means, House of Representatives, 109th Cong. (2005) (Testimony of David M. Walker). Retrieved from https://www.gao.gov/assets/gao-05-743t.pdf

Pennel, C.L., McLeroy, K.R., Burdine, J.N., \& Matarrita-Cascante, D. (2015). Nonprofit hospitals' approach to community health needs assessment. American Journal of Public Health, 105(3), e103-e113. https://doi.org/10.2105/ajph.2014.302286 
Powell, R.E., Doty, A.M.B., Rising, K.L., Karp, D.N., Baehr, A., \& Carr, B.G. (2018) A content analysis of nonprofit hospital community health needs assessments and community benefit implementation strategies in Philadelphia. Journal of Public Health Management and Practice, 24(4), 326-334.

Rich, K.T., Roberts, B.L., \& Zhang, J.X. (2021). Linguistic tone of management discussion and analysis disclosures and the municipal debt market. Journal of Public Budgeting, Accounting \& Financial Management, ahead-of-print(ahead-of-print). https://doi.org/10.1108/jpbafm-11-2019-0168

Rozier M.D. (2020). Nonprofit hospital community benefit in the U.S.: A scoping review from 2010 to 2019. Frontiers in Public Health, 8, 72. https://doi.org/10.3389/fpubh.2020.00072

Singh, S.R. (2013). Not-for-profit hospitals' provision of community benefit: is there a trade-off between charity care and other benefits provided to the community? Journal of Health Care Finance, 39(3), 42-52.

Singh, S.R., \& Young, G.J. (2017). Tax-exempt hospitals' investments in community health and local public health spending: Patterns and relationships. Health Services Research, 52, 2378-2396. https://doi.org/10.1111/1475-6773.12739

Singh S.R., Young, G.J., Loomer, L., \& Madison, K. (2018). State-level community benefit regulation and nonprofit hospitals' provision of community benefits. Journal of Health Politics, Policy and Law, 43(2), 229-269.

Smith, K. (2017). Tell me more: A content analysis of expanded auditor reporting in the United Kingdom. Retrieved from https://ssrn.com/abstract=2821399 or http://dx.doi.org/10.2139/ssrn.2821399

Tao, D., Freeman, M., \& Evashwick, C. (2010). Evidence-based policy and practice on community benefit: Information support for developing a bibliography. Journal of the Medical Library Association, 98(2), 164-167. https://doi.org/10.3163/1536-5050.98.2.010

Tetlock, P. (2007). Giving content to investor sentiment: the role of media in the stock market. Journal of Finance, 62, 1139-1168.

Wang, T., \& Wambsganns, J.R. (1996). Is your organization's tax-exempt status at risk? Healthcare Financial Management, (Suppl. 4-9).

Worthy, J.C., \& Anderson, C.L. (2016). Analysis of the community benefit standard in Texas hospitals. Journal of Healthcare Management, 61(2), 94-102.

Young G.J., Flaherty, S., Zepeda, E.D., Singh, S.R., \& Cramer, G.R. (2018). Community benefit spending by tax-exempt hospitals changed little after ACA. Health Affairs, 37, 121-124. 


\section{APPENDIX}

\section{Mercy Hospital of Folsom 2016 Community Benefit Report Excerpt* \\ Community Benefit Planning Process}

Mercy Folsom engages in multiple activities to conduct its community benefit and community health improvement planning process. These include, but are not limited to: conducting a Community Health Needs Assessment with community input at least every three years; using five core principles to guide planning and program decisions; measuring and tracking program indicators; and engaging the Community Health Committee and other stakeholders in the development of the annual community benefit plan and triennial Implementation Strategy.

\section{Community Health Needs Assessment Process}

The most recent Community Health Needs Assessment (CHNA) was completed and adopted by Mercy Folsom in June 2016. The CHNA was conducted through the Sacramento Regional Collaborative Process which included Mercy Folsom, other Dignity Health hospitals in Sacramento, Yolo and Nevada County, Kaiser Permanente, Sutter Health and UC Davis Health System. These health systems all serve the same or portions of the same communities. Nonprofit research consultant, Valley Vision, Inc., was retained to lead the assessment process, based on its local presence and understanding of the greater Sacramento region and experience in conducting multiple CHNAs across an array of communities for nearly a decade.

The objectives of the CHNA were to identify and prioritize community health needs and identify resources available to address those health needs. Data collected and analyzed included both primary or qualitative data, and secondary or quantitative data. To determine geographic locations affected by social inequities, data were compiled and analyzed at the census tract and ZIP code levels. To assess overall health status and disparities in health outcomes, indicators were developed from a variety of secondary data sources which can be found in the complete CHNA. These "downstream" health outcome indicators included measures of both mortality and morbidity such as mortality rates, emergency department visit and hospitalization rates. Health drivers/conditions or "upstream" health indicators included measures of living conditions spanning the physical environment, social environment, economic and work environment, and service environment. Overall, more than 170 indicators were included in the CHNA.

Community input and primary data on health needs were obtained via interviews with service providers and community key informants (including hospital staff, Sacramento County Public Health and community providers) and through focus groups with medically underserved, low-income, and minority populations. Primary data for Mercy Folsom included 29 key informant interviews with 46 participants and 8 focus groups conducted with 57 participants.

An important component of the assessment included the identification of community and hospital resources that might be available to address priority needs. This resource mapping process which identified 150 community resources provided insight on community capacity and potential opportunities for collaborating with partners. The hospital is currently working with some of the resources identified and others are being targeted for future partnership initiatives. 
Mercy Folsom's CHNA was distributed externally to community leaders, government and public health officials, program partners and other agencies and businesses throughout the region, and made available internally to hospital leadership and employees. The complete assessment is available to the public on http://www.dignityhealth.org/sacramento/documents/hospital-reports-addressing-community-healthneeds/mercy-hospital-of-folsom-2016-chna

\section{CHNA Significant Health Needs}

Significant health needs were identified and prioritized by using quantitative and qualitative data which was synthesized and analyzed according to established criteria. This included identifying eight potential health need categories based upon the needs identified in the $2013 \mathrm{CHNA}$, the grouping of indicators in the Kaiser Permanente Community Commons Data Platform (CCDP), and a preliminary review of primary data. Indicators within these categories were flagged if they compared unfavorably to county, state, or Healthy People 2020 benchmarks or demonstrated racial/ethnic disparities according to a set of established criteria. Eight potential health needs were validated as significant health needs for the service area.

Eight significant health needs emerged from the assessment across the hospital's primary service area:

1. Access to Behavioral Health Services: Includes access to mental health and substance abuse prevention and treatment services.

2. Active Living and Healthy Eating: Encompasses all components of healthy eating and active living including health behaviors, associated health outcomes and aspects of the physical environment/living conditions.

3. Safe, Crime and Violence Free Communities: Consists of safety from violence and crime including violent crime, property crimes and domestic violence.

4. Disease Prevention, Management and Treatment: Contains health outcomes that require disease prevention and/or management and treatment including: cancer, cardiovascular disease /stroke, HIV/AIDS/STDs and asthma.

5. Access to High Quality Health Care and Services: Encompasses access to primary and specialty care, dental care and maternal and infant care.

6. Basic Needs (Food Security, Housing, Economic Security, and Education): Includes economic security, food security/insecurity, housing, education and homelessness.

7. Affordable and Accessible Transportation: Includes the need for public or personal transportation options, transportation to health services and options for persons with disabilities.

8. Pollution-Free Living and Work Environments: Contains measures of pollution such as air and water pollution levels.

These health needs appeared in greater magnitude within four focus communities, including Rancho Cordova (95670), Rancho Cordova/LaRiviera/Rosemont (95827), Citrus Heights/Orangevale (95610), and Placerville/Coloma (95667). These four areas of concern are densely populated and home to nearly 153,000 who are highly diverse, have high rates of poverty, low educational attainment, high levels of unemployment, and rent versus own their homes.

Mercy Folsom is addressing or currently developing partnership initiatives to focus on significant health issues identified in the Community Health Needs Assessment that include: 1) access to behavioral health services; 2) active living and healthy eating; 3 ) safe, crime and violence free communities 4) disease prevention, management, and treatment; 5) access to high quality health care; 
and 6) basic needs. Initiatives that address these priorities largely target vulnerable and at-risk populations, with emphasis on identified focus communities and collaboration with other Dignity Health hospitals and community partners to maximize efforts and have a greater region-wide impact. Initiatives also utilize methodologies to measure and demonstrate health improvement outcomes.

Mercy Folsom does not have the capacity or resources to address all priority health issues. The hospital is not directly addressing affordable and accessible transportation or pollution-free living and working environments. Many of the current initiatives include a transportation component, although services are limited. Sacramento Area Council of Governments (SACOG), an association of local governments in the six-county Sacramento Region, focuses on initiatives around transportation planning and clean air initiatives. The hospital will also continue to seek new partnership initiatives to address priority health issues when there are opportunities to make a meaningful impact on health and quality of life in partnership with others.

\section{Creating the Community Benefit Plan}

As a matter of Dignity Health policy, the hospital's community health and community benefit programs are guided by five core principles. All of our initiatives relate to one or more of these principles:

- Focus on Disproportionate Unmet Health-Related Needs: Seek to address the needs of communities with disproportionate unmet health-related needs.

- Emphasize Prevention: Address the underlying causes of persistent health problems through health promotion, disease prevention, and health protection.

- Contribute to a Seamless Continuum of Care: Emphasize evidence-based approaches by establishing operational linkages between clinical services and community health improvement activities.

- Build Community Capacity: Target charitable resources to mobilize and build the capacity of existing community assets.

- Demonstrate Collaboration: Work together with community stakeholders on community health needs assessments, health improvement program planning and delivery to address significant health needs.

A general approach is taken when planning and developing initiatives to address significant health issues. At the onset, Community Health and Outreach staff engages a core internal team that may include clinical staff, care coordinators and social workers, members of the Mercy Folsom leadership team, and Dignity Health leaders at the regional and local levels from Mission Integration, IT, Legal, Administration, and Finance. These core teams help shape initiatives, provide internal perspective on issues (i.e. utilization trends relative to the issue, gaps experienced in available follow-up or wraparound care for patients, etc.) and help define appropriate processes, procedures and methodologies for measuring outcomes.

The planning and development of each initiative also involves research on best practices to identify existing evidence-based programs and interventions, and relationship strengthening with communitybased providers that serve target populations for intended initiatives. Once identified, community-based partners become part of the hospital's core project team. Core project teams for all initiatives meet quarterly, or as needed, to evaluate program progress and outcomes, and to make program changes and/or improvements. 


\section{Economic Value of Community Benefit}

The following FY 2016 (for period from 7/1/2015 through 6/30/2016) Classified Summary of Unsponsored Community Benefit Expense for Mercy Folsom was calculated using a cost accounting methodology.

\begin{tabular}{|c|c|c|c|c|c|}
\hline Benefits for Living in Poverty & $\begin{array}{c}\text { Persons } \\
\text { Served }\end{array}$ & $\begin{array}{c}\text { Total } \\
\text { Expenses }\end{array}$ & $\begin{array}{l}\text { Offsetting } \\
\text { Revenue }\end{array}$ & $\begin{array}{c}\text { Net } \\
\text { Benefit }\end{array}$ & $\begin{array}{c}\% \text { of } \\
\text { Organization } \\
\text { Expenses }\end{array}$ \\
\hline Financial Assistance & 971 & 663,087 & 52,244 & 610,843 & 0.3 \\
\hline Medicaid & 19,056 & $39,587,762$ & $26,024,973$ & $13,562,789$ & 7.3 \\
\hline Means-Tested Programs & 3 & 14,364 & 8,336 & 6,028 & 0.0 \\
\hline \multicolumn{6}{|l|}{ Community Services } \\
\hline $\begin{array}{l}\text { A - Community Health Improvement } \\
\text { Services }\end{array}$ & 2,447 & 151,500 & 16,616 & 134,884 & 0.1 \\
\hline C - Subsidized Health Services & 840 & 373,887 & 0 & 373,887 & 0.2 \\
\hline E - Cash and In-Kind Contributions & 74 & 152,044 & 0 & 152,044 & 0.1 \\
\hline F - Community Building Activities & 0 & 1,817 & 0 & 1,817 & 0.0 \\
\hline G - Community Benefit Operations & 0 & 139,827 & 0 & 139,827 & 0.1 \\
\hline Totals for Community Services & 3,361 & 819,075 & 16,616 & 802,459 & 0.4 \\
\hline Totals for Living in Poverty & 23,391 & $41,084,288$ & $26,102,169$ & $14,982,119$ & 8.1 \\
\hline Benefits for Broader Community & $\begin{array}{c}\text { Persons } \\
\text { Served }\end{array}$ & $\begin{array}{c}\text { Total } \\
\text { Expenses }\end{array}$ & $\begin{array}{l}\text { Offsetting } \\
\text { Revenue }\end{array}$ & $\begin{array}{c}\text { Net } \\
\text { Benefit }\end{array}$ & $\begin{array}{c}\% \text { of } \\
\text { Organization } \\
\text { Expenses }\end{array}$ \\
\hline \multicolumn{6}{|l|}{ Community Services } \\
\hline $\begin{array}{l}\text { A - Community Health Improvement } \\
\text { Services }\end{array}$ & 825 & 24,181 & 0 & 24,181 & 0.0 \\
\hline B - Health Professions Education & 258 & 560,183 & 0 & 560,183 & 0.3 \\
\hline E - Cash and In-Kind Contributions & 10 & 252,034 & 0 & 252,034 & 0.1 \\
\hline F - Community Building Activities & 1 & 22,642 & 0 & 22,642 & 0.0 \\
\hline Totals for Community Services & 1,094 & 859,040 & 0 & 859,040 & 0.5 \\
\hline Totals for Broader Community & 1,094 & 859,040 & 0 & 859,040 & 0.5 \\
\hline Totals - Community Benefit & 24,485 & $41,943,328$ & $26,102,169$ & $15,841,159$ & 8.6 \\
\hline Medicare & 9,525 & $\mathbf{5 0 , 2 6 5 , 3 3 9}$ & $36,016,733$ & $14,248,606$ & 7.7 \\
\hline Totals Including Medicare & 34,010 & $92,208,667$ & $62,118,902$ & $30,089,765$ & 16.2 \\
\hline
\end{tabular}

*Full report (33 pg.) available at: https://data.chhs.ca.gov/dataset/community-benefit-plans 